\title{
QUENCH CRACKING CHARACTERIZATION OF SUPERALLOYS USING FRACTURE MECHANICS APPROACH
}

\author{
Jian Mao", Keh-Minn Chang ${ }^{*}$ and David Furrer** \\ * West Virginia University, Morgantown, WV 26506 \\ **Ladish Co., Inc., Cudahy, WI 53110
}

\begin{abstract}
In the expectation of developing a new quench cracking criterion, an approach based on fracture mechanics has been investigated in order to improve computer modeling of quenching process. A fully automatic computer controlled data acquisition and processing system was set up to simulate the quenching process. Based on the study of the quench cracking resistance of several gamma prime strengthened superalloys, including $U 720 \mathrm{Li}$, Rene'95, Rene88DT and HW model alloys, the mechanism of quench cracking was studied. Effects of the grain size, solution temperature, the composition of alloy as well as specimen size on quench cracking resistance have been investigated. Results show that quench cracking is featured with intergranular failure. The quench cracking toughness and the failing temperature is related to the quench fracture mode. There is a transition in fracture modes with the decrease of temperature. Grain size, composition and solution temperature were found to be the three major factors influencing quench cracking resistance. Fine grain structure can sustain more tcmpcrature drop and requires higher thermal stress to initiate the cracking. Intermediate grain structure, which was heated at either supersolvus or subsolvus temperatures, failed at higher temperature and hence developed lower quench toughness. $\gamma^{\prime}$ content in alloys only influences the cracking resistance of subsolvus quenched specimen, but does not show significant influence on that of supersolvus quenched one.
\end{abstract}

\section{$\underline{\text { Introduction }}$}

PM superalloys and their application on turbine disk have matured since the 1970's. With the development of computer simulation technology, modeling of thermal and stress fields has further enabled improved process control in powder consolidation, forging, heat treatment and other processes [1-3]. Precise prediction of microstructure and mechanical properties has shown bright perspective [4-7]. However, the risk of quench cracking and distortion due to aggressive thermal stress still remains a concern in the supcralloy community. Unexpected quench cracking on the practical disks usually results in a huge waste of money.

In the past few years, efforts in computer simulation of heat treatment have been focusing both on acquiring high strength in quenched parts and on avoiding quench cracking and scvere distortion [8-11]. So far, the calculation of cooling rates and the prediction of mechanical properties in the quenching part are expanding. Comparing to practice in real situation, however, the simulation sometimes fails to produce reliable predictions on quench cracking. The problem is that the present computer simulation uses the cracking criterion that is based on strength consideration, i.e., if the thermal stress in a quenching part exceeds the strength limit, cracking is predicted to occur. No consideration about the surface defects on heat treated parts is included. In fact, several kinds of defects are unavoidably existent on the surface. These include, machining scratches, oxidation scales, inclusions, micro-cracks and other discontinuities. Therefore, modeling based on strength criterion cannot treat the scatter due to the variations in surface defects [12]. Moreover, an alloy with the highest strength actually shows the lowest cracking resistance [13].

Taking into account these surface defects and the weakness of the strength criterion, a new approach based on fracture mechanics has been investigated in the expectation of developing a new quench cracking criterion [13-15]. Based on the study of the quench cracking resistance of several gamma prime strengthened superalloys, including U720Li, Rene'95, Rene88DT and HW model alloys, the mechanism of quench cracking has been studied. Effects of grain size, solid solution temperature, composition of alloys as well as specimen size on quench cracking resistance have also been examined. 
Table I Composition of the superalloys, wt $\%$

\begin{tabular}{l|c|c|c|c|c|c|c|c|c|c|c|c|c}
\hline Alloy & $\mathrm{C}$ & $\mathrm{W}$ & $\mathrm{Mo}$ & $\mathrm{Nb}$ & $\mathrm{Zr}$ & $\mathrm{Co}$ & $\mathrm{Al}$ & $\mathrm{Cr}$ & $\mathrm{Ti}$ & $\mathrm{B}$ & $\mathrm{Ni}$ & $\gamma^{3} \%$ at $650^{\circ} \mathrm{C}$ & $\mathrm{T} \gamma^{\prime}{ }_{\mathrm{s}}$ \\
\hline PMU720Li & 0.025 & 1.3 & 3.02 & & 0.035 & 14.75 & 2.46 & 16.35 & 4.99 & 0.017 & $\mathrm{Bal}$ & 46.4 & 1150 \\
CWU720Li & 0.013 & 1.18 & 2.85 & & 0.03 & 14.45 & 2.48 & 16.14 & 5.15 & 0.014 & $\mathrm{Bal}$ & 47.3 & 1161 \\
Rene88DT & 0.049 & 3.88 & 4.00 & 0.70 & 0.043 & 12.99 & 1.99 & 15.67 & 3.72 & 0.016 & $\mathrm{Bal}$ & 38.6 & 1100 \\
Rene'95* & 0.06 & 3.5 & 3.5 & 3.5 & 0.05 & 8.0 & 3.5 & 13.0 & 2.5 & 0.015 & $\mathrm{Bal}$ & 54.5 & 1150 \\
HW1** & & & 4.0 & & 0.05 & 10.0 & 1.5 & 15.0 & 3.0 & 0.01 & $\mathrm{Bal}$ & 26.1 & 990 \\
HW3** & & & 4.0 & & 0.05 & 10.0 & 2.0 & 15.0 & 4.0 & 0.01 & $\mathrm{Bal}$ & 36.7 & 1080 \\
\hline
\end{tabular}

*Data is from Ref. 12

**Nominal composilion

\section{Materials and Experimental Procedure}

The materials studied were U720Li, Rene'95, Rene88DT and HW model alloys. Bulk composition of these alloys is listed in Table 1. PM U720Li, Rene88DT and Rene'95 are commercial powder metallurgy superalloys made by standard production procedure, HIP + extrusion + isothermal forging. Cast and wrought U720Li alloys were also investigated. HW alloys are cast \& wrought model alloys designed for the study of $\gamma^{\prime}$ content effect. All these alloys are strengthened by the precipitation of $\gamma^{\prime}$. The amount of $\gamma^{\prime}$ in alloys varies from $25 \%$ to $55 \%$. $\gamma^{\prime}$ content and the $\gamma^{\prime}$ solvus temperature for those alloys were calculated by using Thermo-Calc software, vision $\mathrm{M}$, NiFe database 3.0 with 13 elements. This calculated temperature was used to establish subsolvus and supersolvus treatments.

The tests were carried out on a servo-control MTS machine. A fully automated computer control and data acquisition system was set up for the machine. The machine is capable of heating and cooling the specimen accurately at designated rates because of the infrared radiant heating equipped furnace. The specimen has a dog-bone shape with a rectangular cross section of $6.35 \mathrm{~mm}(0.25$ inch) by $1.27 \mathrm{~mm}(0.05 \mathrm{inch})$, and a gauge length is $44.45 \mathrm{~mm}(1.75$ inch). A single edge notch was made by EDM. The notch depth is $0.635 \mathrm{~mm}(0.025$ inches $)$. Precracking was carried out at room temperature to avoid the influence of the starting notch geometry. Most of the precrack lengths were controlled to meet: $0.45<\mathrm{a} / \mathrm{w}$ $<0.55$ (w: width of specimen, a: crack length) in this study.

During the quenching test, each specimen was held on the MTS machine and heated up to a designated solution temperature. After holding at this temperature for one minute, the quench process was activated with the setting of the grips at displacement control mode. Thermal load was then applied instantly due to the contraction of the specimen. When the on-cooling thermal stress (load) accumulated to a certain point, quench cracking happened abruptly. Based on the precrack length, the thermal stress was converted to toughness $K$ according to the Tada's empirical equation, which is stated below, [16] and then the on-cooling K-T curve can be plotted. On the K-T curve, the temperature at which maximum $\mathrm{K}$ was reached was defined as a failing temperature $\left(T_{f}\right)$. The value of $K$ at this point was defined as quench cracking toughness $\mathrm{K}_{\mathrm{Q}}$.

$$
K=\frac{P}{B \sqrt{W}} \frac{\sqrt{2 \tan \frac{\pi a}{2 w}}}{\cos \frac{\pi w}{2 w}}\left[0.752+2.02\left(\frac{a}{w}\right)+0.37\left(1-\sin \frac{\pi a}{2 w}\right)^{3}\right]
$$

Where: a - measured precrack length

W- width of specimen

$\mathrm{B}$ - thickness of specimen

$\mathrm{P}$ - maximum load while cracking

Metallographic samples were taken from broken quench specimens in the area adjacent to the fracture surface parallel to the stress axis. Chemical etching was used to study grain structures. The chemical etchant used is: $50 \% \mathrm{HCL}+50 \% \mathrm{H}_{2} \mathrm{O}+$ $0.5 \% \mathrm{H}_{2} \mathrm{O}_{2}$. Electrolytic-etch was used to reveal the $\gamma^{\prime}$ morphology. This etchant is Chromium Acid Solution $\left(170 \mathrm{mlH}_{3} \mathrm{PO}_{4}+16 \mathrm{gCrO}_{3}\right.$ $\left.+10 \mathrm{mlH}_{2} \mathrm{SO}_{4}\right)$. Fracture morphology of broken specimens and precipitate distribution were observed using scanning electron microcopy (SEM).

\section{$\underline{\text { Result and discussion }}$}

\section{Simulation of the quench cracking process}

Quench cracking is a type of abrupt failure. Figure 1 shows the scheme of a quench process and the plot of the cooling curve. Simulation of the process indicates that with the temperature decrease during cooling, the thermal load increases rapidly to a maximum value, then the catastrophic failure happens and the specimen is broken into two pieces.

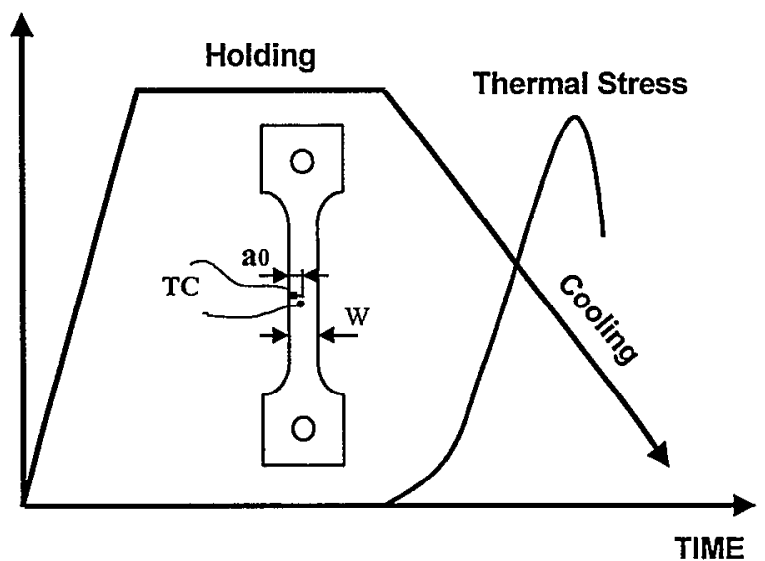

Figure 1: Scheme of quench process and plotting of on-cooling curve 
Examination of the fracture surface indicates that quench cracking is characterized with a typical brittle intergranular fracture mode, as shown in Figure 2, which is consistent with the quench cracking failure mode in actual disks. This intergranular fracture feature differs from the precracking one, as shown on the right hand side of the Fig.2, which is typically transgranular. It is also different from that observed in the tensile or stress rupture tests at elevated temperatures, which is usually an intergranular dimple mode for most superalloys. This demonstrates that the quench simulating system based on the new fracture mechanics approach can well represent the real quench cracking process.

\section{Quench cracking toughness and cracking mode}

The measurement of the cracking toughness of alloys demonstrates that there is a relationship between the quench cracking toughness and the failing temperature. Figure 3 shows the results obtained from PMU720Li and CWU720Li alloys. Generally speaking, if the cracking occurs at a higher temperature, above $800^{\circ} \mathrm{C}$, lower cracking toughness is obtained. In contrast, if material fails at a lower temperature, it usually results in higher cracking toughness. This relationship is associated with the quench fracture mode.

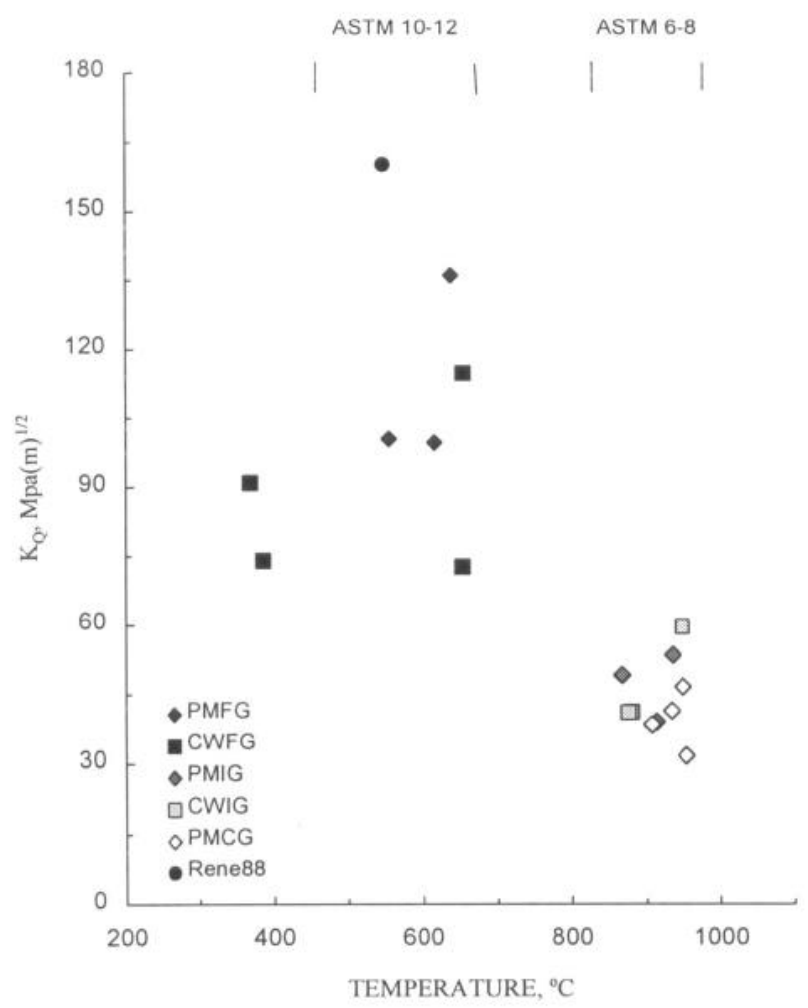

Figure 3: Relationship of failing temperature and quench cracking toughness

As mentioned above, intergranular fracture feature is a predominant cracking mode observed in quench cracking. This type of failure usually happens at a higher temperature $\left(\mathrm{T}_{\mathrm{f}}>\right.$ $\left.800^{\circ} \mathrm{C}\right)$ and is featured with lower quench toughness $\left(\mathrm{K}_{\mathrm{Q}}=40\right.$ $60 \mathrm{MPa} \sqrt{\mathrm{m}}$ ). In addition to that, two more types of cracking features were observed during the SEM examination. One is that the quench cracking initiates intergranularly and then transfers to a transgranular mode, as shown in Figure 4. In this case, the failing temperature drops down to about $500^{\circ} \mathrm{C}-700^{\circ} \mathrm{C}$, cracking toughness is raised up to more than $70 \mathrm{MPa} \sqrt{\mathrm{m}}$. The third mode is completely transgranular, as shown in Figure 5, which looks like what we see in the tensile test. The failing temperature, in this case, is lower than $500^{\circ} \mathrm{C}$, where the quench cracking toughness is observed to be even higher.

Fractography examinations indicate that there is a transition in fracture modes with the decrease of temperature during the quenching test. This temperature at which fracture mode switches bears great importance for the quench process control and is worth further investigation.

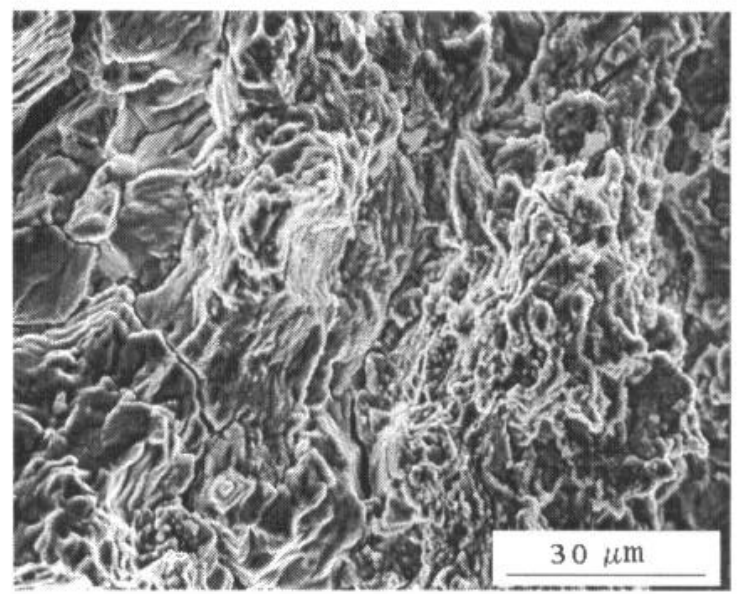

Figure 5. Completely transgranular failure in $\mathrm{HW} 1$ alloy, Solution temperature $1000^{\circ} \mathrm{C}$, Cooling rate $600^{\circ} \mathrm{C} / \mathrm{min}$

\section{$\underline{\text { Characterization of quench behaviors }}$}

As a characteristic parameter, quench cracking resistance varies with the microstructure, composition of alloys and solution temperature as well as cooling rate. Their influence is discussed respectively below.

Grain size effect The influence of grain size is accomplished through the deformation behavior and fracture mode at high temperatures. Figure 6 shows grain structures of PM U720Li and cast \& wrought U720Li superalloys, where FG represents the fine grain structure with a grain size ASTM11-12. IG, CG represents a similar grain structure with a grain size ASTM 7-8, both obtained by supersolvus treatment before our quench tests. The difference is that CG was designated for a supersolvus solution in our quench test and IG was for a subsolvus solution. Grain size effects are demonstrated by comparing different structures from the same alloy, as shown in Figure 3. Specimens with fine grain structure tend to fail at a lower temperature and were characterized mainly with the II or III type fracture feature. As a result, higher quench cracking toughness is obtained. That indicates that fine grain structure can sustain more temperature drop and requires higher thermal stress to initiate the cracking. Specimens with coarse grain structures, no matter what temperature they were heated to, either supersolvus or subsolvus, all failed at higher temperatures and had the lower cracking toughness. The effect of the grain size on the quench crack toughness is related to the stress relaxation 

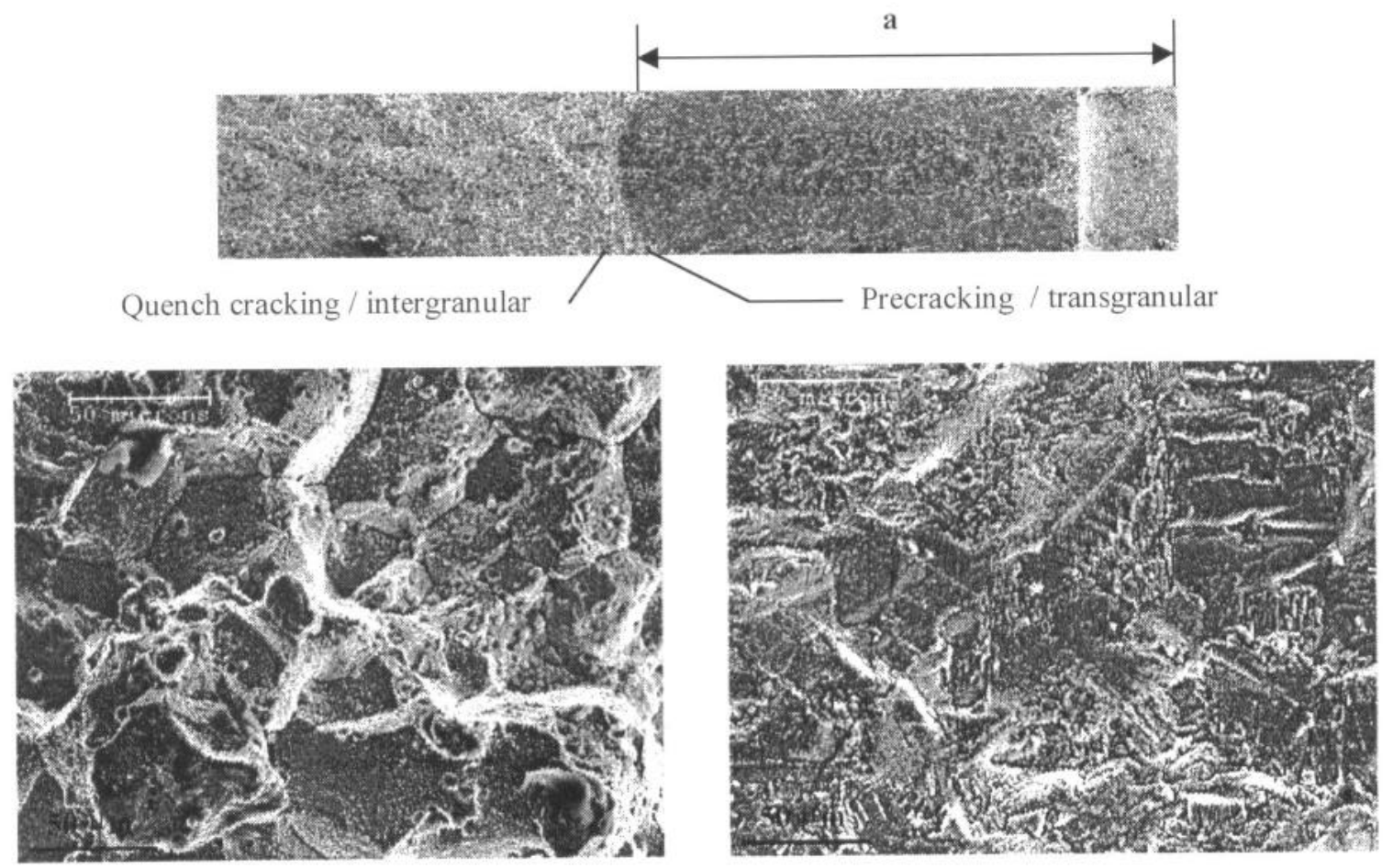

Figure 2: Typical fracture morphology observed in quench cracked specimen with coarse grain structure

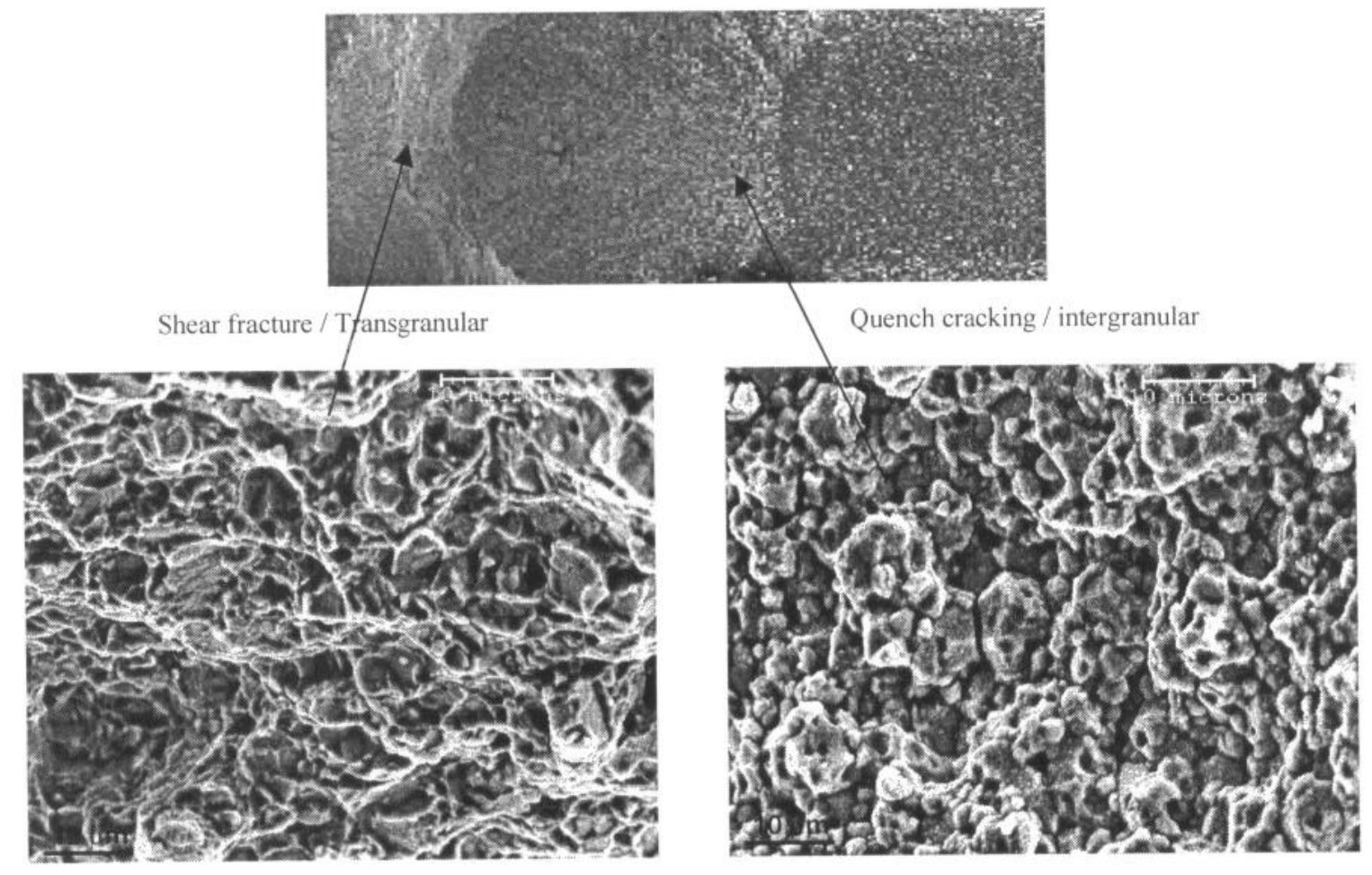

Figure 4: Transition of fracture mode from intergranular to transgranular in fine grain structure 

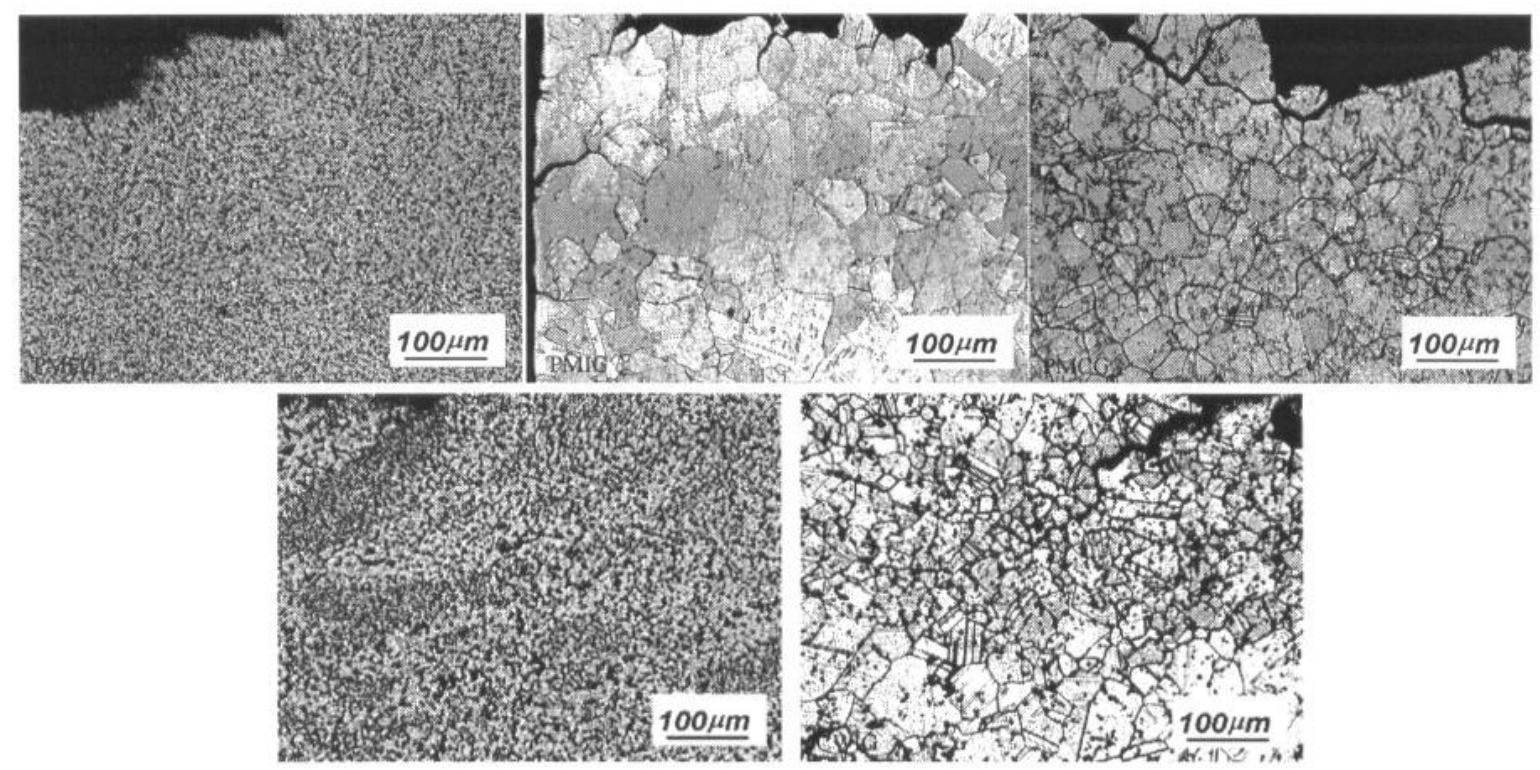

Figure 6 Grain structure of PM and CW Udimet 720Li superalloy after quenching test

capability of the structure in response to the thermal stress.

The topographic factor of crack propagation also contributes to the difference. In addition, a fractographic examination reveals that there are many secondary cracks found in the specimen with the fine grain structure. The development of abundant secondary cracks also contributes to a higher fracture toughness. It is believed that the value of the cracking toughness for different microstructures may vary with different alloys, but the grain size effect might always exist.

Solution temperature effect Solution temperature is another key factor to be considered in the study of the quench cracking behavior. Supersolvus solution provides alloys with preferred fatigue crack growth resistance [17-20]. Therefore, supersolvus heat treatment is favored for second or third generation PM superalloys. However, the quench cracking resistance under the supersolvus condition is inferior. Figure 7 shows a typical oncooling K-T curve for supersolvus temperature quenching. All the specimens for the studying of solution temperatures and composition have almost the same grain size, ASTM 7-8. Supersolvus quenching carries lower quench cracking toughness than subsolvus treatment and usually fails abruptly at higher temperatures, above $800^{\circ} \mathrm{C}$. The fracture feature is of an intergranular mode. Moreover, the quench cracking resistance seems to be somewhat alloy independent. All the specimens demonstrate the same cracking behavior regardless of alloy composition: cracking toughness is between 40-60 MPa $\sqrt{\mathrm{m}}$, failing temperature above $800^{\circ} \mathrm{C}$ and each featured intergranular failure. It is believed that the normalization of microstructure and the weakening of the grain boundary at elevated temperatures plays the main role in composition independence for supersolvus quenching.

The subsolvus quench shows not only higher cracking toughness but also dependence on the composition of alloys.
Figure 8 shows some typical K-T curves for subsolvus quenching. The value of the quench cracking toughness varies from $30 \mathrm{Mpa} \sqrt{\mathrm{m}}$ to $120 \mathrm{Mpa} \sqrt{\mathrm{m}}$ with different alloys having almost the same grain structure and grain size ASTM 7-8. Solution temperature effect is believed to be associated with the balance of cracking resistance between the grain boundary and the intragranular area.

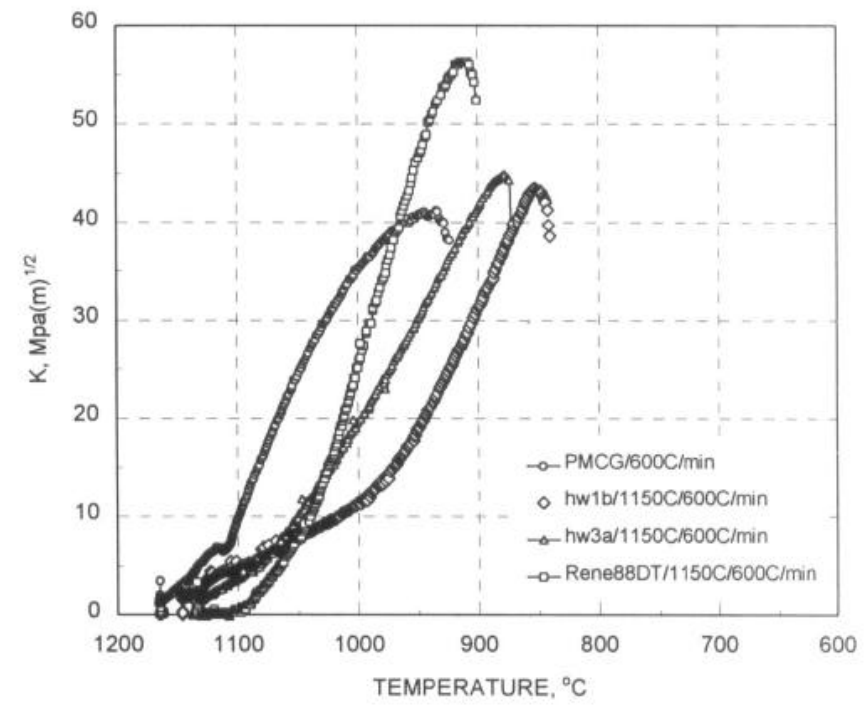

Figure 7: Typical on-cooling K-T curve for supersolvus temperature quenching 


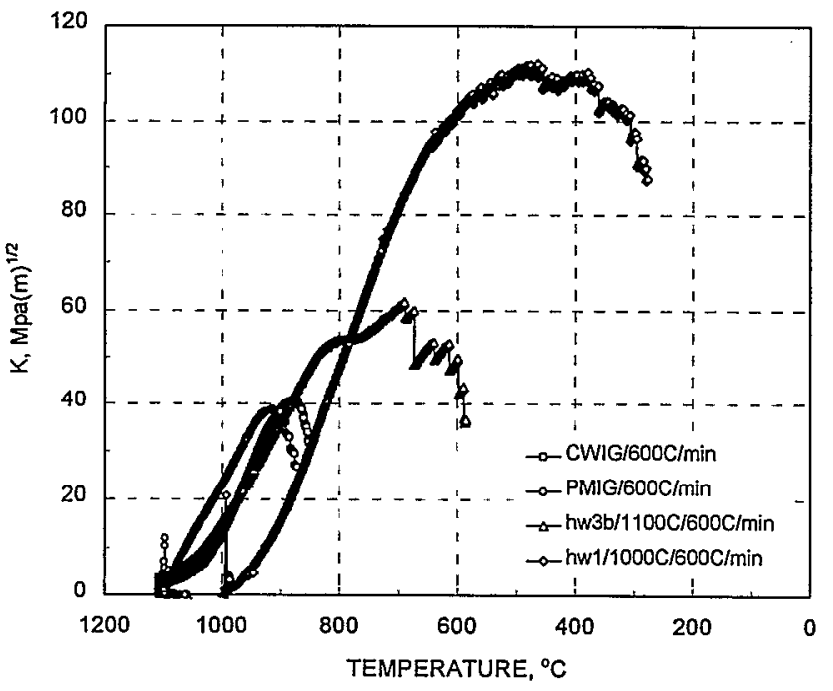

Figure 8 Typical on-cooling curve for subsolvus temperature quenching

Composition effect Several superalloys are chosen in order to study the composition effect on quenching behavior. Composition differences cause a different volume fraction of $\gamma^{\prime}$ phase in the alloys. The volume fraction of gamma prime in the alloys was simulated by using Thermo-Calc software. The volume fraction of gamma prime is taken as the amount at $650^{\circ} \mathrm{C}$ according to the calculation, listed in Table I. Figure 9 displays the gamma prime solubility with the temperature in various superalloys. The HW1 is the alloy with lowest gamma prime content. The volume fraction of gamma prime is about $27 \%$. Rcne' 95 has the highest gamma prime content, at about $56 \%$. As we mentioned above, the alloy with different gamma prime content does not show a difference on cracking toughness during a supersolvus treatment. But during a subsolvus treatment, the effect of the gamma prime content and solubility of alloys on cracking behaviors are obvious. Figure 10 shows the relationship of $\gamma^{\prime}$ content and the quench cracking resistance as well as failing temperature. Data of Rene'95 alloy was taken from ref.13. If an alloy is highly alloyed

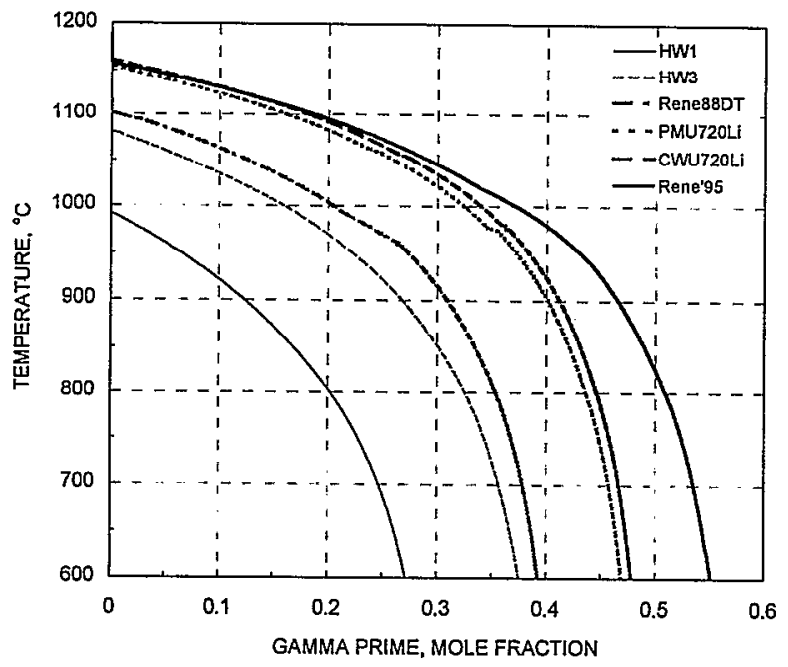

Figure 9 Gamma prime solubility with temperature in superalloys

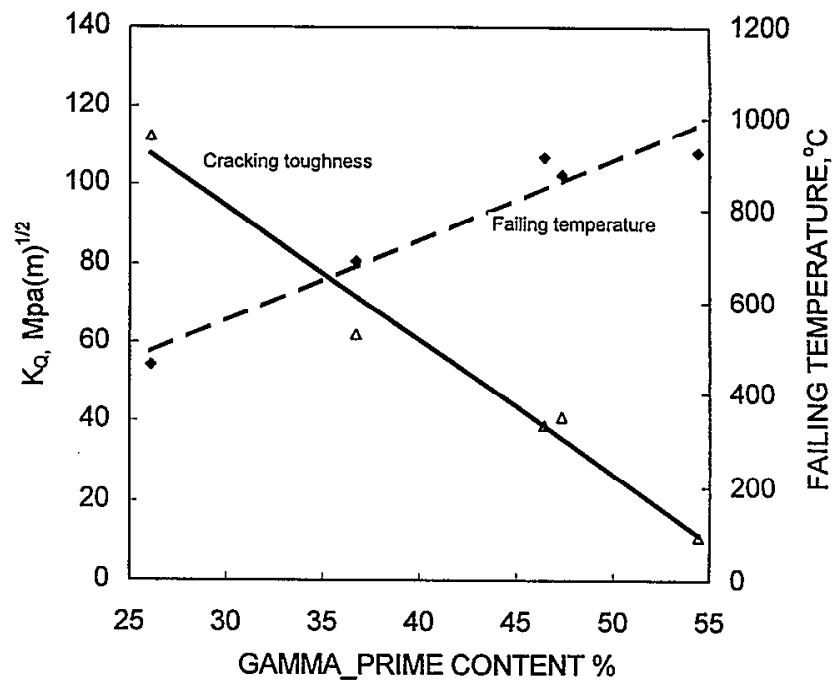

Figure 10: Effect of $\gamma^{\prime}$ content on quench cracking toughness and failing temperature

to obtain a higher $\gamma^{\prime}$ fraction, it will more likely exhibit a higher failing temperature and lower quench cracking toughness. A less alloyed alloy, having low $\gamma^{\prime}$ fraction, tends to fail at lower temperature and shows higher quench cracking toughness.

Specimen size effect Besides the influence of the above factors on quench cracking behaviors, the size of the specimen is another consideration. A narrow specimen with a cross section of $3.175 \mathrm{~mm}\left(0.125^{\prime \prime}\right) \times 1.27 \mathrm{~mm}\left(0.05^{\prime \prime}\right)$, which is half of the width of normal specimen, is used to study the specimen size effects. Alloys investigated are the same as used in the grain size study. As we can sce in Figure 11, decreasing the width of the specimen usually lowers the cracking toughness, especially for fine grain structure. One of the reasons for this is that narrow specimen mean a shorter effective length for crack propagation and a limited accumulation of thermal stress. Before $K$ can reach higher values, failure of the specimens already occurs. Another reason is that narrow specimen results in more stress relaxation. So it's hard to reach higher stress. The investigation of the specimen size effect is still underway.

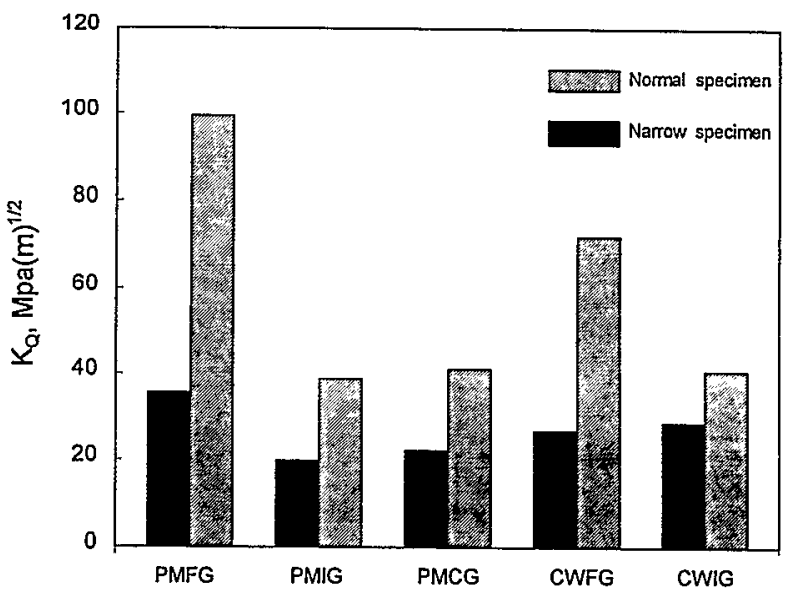

Figure. 11 Effect of the specimen size on cracking toughness Discussion 
Microstructure and deformation

Quench cracking behavior at elevated temperatures is believed to be associated with the deformation behavior of materials. Softening and hardening are considered as two typical processes during high temperature deformation. Figure 12 summarizes schematically the development of the on-cooling thermal load on specimens for various test conditions. At the very beginning of quenching, the rate of thermal stress increase is slow. The curvatures of thermal load vs temperature (L-T) curves are negative, which means that softening dominates the deformation process. With further decrease in temperature, the curvatures of L$\mathrm{T}$ curves change from negative to positive, the hardening process gradually outweighs the softening process until cracking.

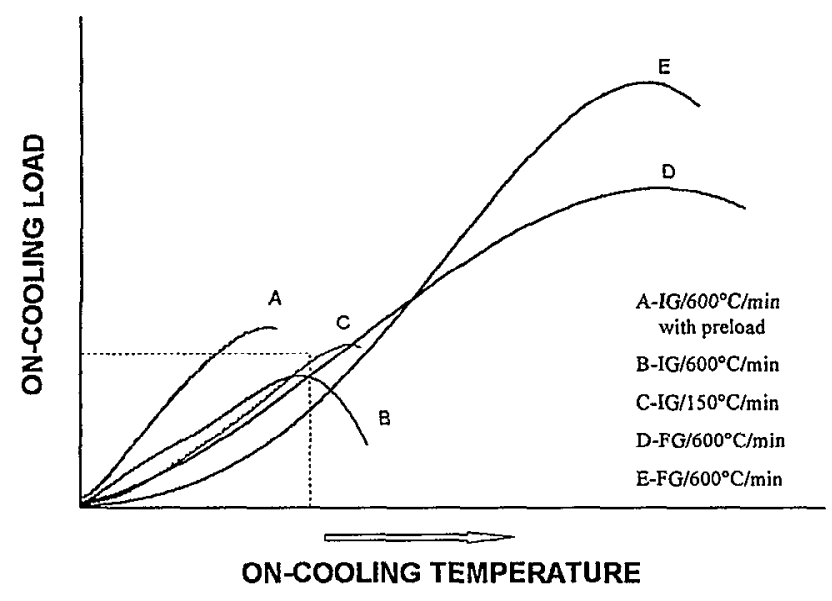

Figure 12: Scheme of the development of on-cooling thermal load

The curvature of L-T curves differs from fine grain structure to coarse grain structure. For all specimens, the curvatures on the L-T chart increase at beginning as the cooling rates decrease. As we know, fine grain is more flexible and compliant under stressful conditions. Therefore, softening in the fine grain structure is more severe than that in the coarse grain structure under the same cooling rate for the same material (see inside dashed line area in Figure 12). Furthermore, because the softening process consumes a lot of energy at the beginning of quenching, and the hardening process is postponed, so the specimen with fine grain structure can survive through the fracture mode transition temperature. The transition of fracture modes allows these specimens to resist more thermal stress before reaching a critical point. That is one of the reasons why fine grain structure shows higher cracking toughncss and lower failing temperature for the same material.

The topographical factor of the crack path in the fine grain structure is another beneficial factor that brings in higher cracking toughness [13]. Once a crack initiates, the size and direction of grain features influence its propagation along the grain boundary. Therefore the fine grain structure can absorb much more cracking energy, taking more time to reach the critical fracture limitation before a catastrophic failure. In fact, when the temperature drops sufficiently, intergranular cracking is actually depressed by the precipitation of strengthening phases and the transition of the fracture mode takes place. Secondary cracks also appear to have some beneficial effects on energy release before final failure.
Lower cracking toughness of the coarse grain structure is due to its lack of compliance. Because of this, accumulation of thermal stress is faster than in the fine grain structure. As a result, hardening process dominates most of the cooling process. Before samples cool down to the transition temperature of failure modes, rapidly increasing thermal stress has already reached a critical value. On the other hand, because coarse grain provides less grain intersection obstruction to crack propagation and less grain boundaries to absorb cracking energy, once a crack initiates, unrestricted propagation along the grain boundary will continue to the end of the fracture path.

A lower cooling rate causes more softening at the beginning of the quenching process. Therefore, lower cooling rates result in higher quench cracking toughness in both fine and coarse grain structure samples.

If there are more grain boundaries, a lower cooling rate, a higher degree of softening, and more cnergy is released at the beginning of quenching, then there is more potential for the alloy to survive through the fracture mode transition temperature. A higher quench cracking toughness would be expected for this material. Grain size effect and brittle / ductile fracture transition was also found in the investigation of Rene'95 alloy [13]. In that study, a transition temperature of $700^{\circ} \mathrm{C}-850^{\circ} \mathrm{C}$ was suggested. The delayed transfer of production components from the heat treat furnace to the quench bath can help to avoid quench cracking. This may be due to the postponement of the hardening process, which allows the components to survive the transition temperature of fracture modes.

\section{Balance of strengthening in grain boundary and matrix}

As indicated before, supersolvus treatments usually feature intergranular failure, which results in lower cracking toughness. The reason is related to the balance of cracking resistance between the grain boundary and the matrix at high temperatures. During supersolvus treatment, all the $\gamma^{\prime}$ forming elements dissolve into the matrix. The material is highly solution strengthened. In this case, the grain boundaries become relatively weak, so it becomes the preferred path for crack propagating [12]. Moreover, since no $\gamma^{\prime}$ precipitates along the grain boundaries, it facilitatcs the crack propagation along the grain boundary. In addition, grain boundary micro-cracks due to oxidation at high temperatures may be another considerable factor [12].

Subsolvus treatment and some strengthening phases, like $\gamma^{\prime}$, precipitate from the matrix along grain boundaries, which weaken the solid strengthening of the intragranular area, but strengthen the grain boundaries. If grain boundaries are strengthened enough, it is possible for the intragranular area to become potential crack propagation paths when intergranular crack propagation is obstructed. This is proven by the observation of the fractography of the specimen after a subsolvus treatment. Most of the broken specimens for the subsolvus solution, regardless of the composition of alloys, are found undergoing the transition in fracture modes. Furthermore, for subsolvus treatment, once the fracture mode is transferred to the transgranular mode, the amount of primary or secondary $\gamma^{\prime}$, the size of $\gamma^{\prime}$, the mismatch of lattice and carbide content etc. will affect the fracture strength of the alloy. The lower $\gamma^{\prime}$ content alloy has less $\gamma^{\prime}$ forming elements which results in lower solution strengthening. Therefore, higher 
cracking resistance is obtained, as seen in Fig.10. That is why composition effects are obvious for subsolvus treatment. Topographic effect of primary $\gamma^{\prime}$ on the grain boundary is another important reason to slow down and block the cracking growth along the grain boundary.

\section{Conclusions}

A new fracture mechanics approach provides a way to quantitatively evaluate the quench cracking resistance of superalloys. Grain size, composition, and solution temperature are found to be the three major factors influencing quench cracking resistance and quench behavior.

The fracture mode affects the quench cracking resistance of alloys. Complete intergranular failure is usually concomitant with a lower cracking toughness. If an alloy can survive the intergranular cracking mode, or be able to cool down below the transition temperature of cracking modes, a higher cracking resistance is expected.

The alloy with higher $\gamma^{\prime}$ content shows lower quench cracking resistance than alloy with a lower $\gamma^{\prime}$ volume fraction under the same test condition and similar grain structure.

Solution temperatures influence the quench cracking resistance of $\gamma^{\prime}$ strengthened superalloys. Supersolvus solutions more likely cause intergranular cracking. Subsolvus solutions increase the possibility of fracture mode transition and show relatively higher quench cracking toughness. The influence of solution temperatures is associated with the balance of the fracture resistance between the grain boundary and the intragranular area. The topographic factor of primary $\gamma^{\prime}$ on the grain boundary and the grain boundary oxidation resistance may also affect quench cracking resistance.

\section{Reference:}

[1] T. Furman and R. Shankar, "Keys to Modeling the Forging Process," Advanced Materials \& Processes, 154 (3) (1998) 45-46

[2] C.P.Blankenship, Jr., M.F.Henry, J.M.Hyzak, et al., "Hot-Die Forging of P/M Ni-Base Superalloys," Superalloy 1996, ed. R.D.Kissinger et al. The Minerals, Metals and Materials Society (1996) 653-662

[3] D.J.Bryant, Dr.G.McIntosh, "The Manufacture and Evaluation of A Large Turbine Disk in Cast and Wrought Alloy 720Li," Superalloy 1996, ed. R.D.Kissinger et al. The Minerals, Metals and Materials Society (1996) 713-722

[4] N.Gayraud, F.Moret, X.Baillin and P.E.Mosser, "Precipitation Kinetics in N18 P/M Superalloy: Experimental Study and Numerical Modeling," Joumal de Physique III, 3 (1993) 271-276

[5] J. J. Schirra and S. H.Goetschius, "Development of An Analytical Model Predicting Microstructure and Properties Resulting from the Thermal Processing of A Wrought Powder Nickel-Base Superalloy Component," Superalloys 1992, ed. S.D.Antolovich et al. The Minerals, Metals and Materials Society (1996) 437-446
[6] M.P.Jackson, R.C.Reed, "Hcat Treatment of Udimet 720Li: the effect of microstructure on properties," Materials Science and Engineering, 259 (A) (1999), 85-97

[7] David Furrer and H.Fecht, "Ni-Base Superalloys for Turbine Dises," JOM, 1999, no 1: 33-36

[8] Ronald A. Wallis, "Modeling Quenching: the state of the art," Advanced Materials \& Processes, 1995, no.9: 42kk-42NN

[9] R.A. Wallis and I.W.Craighead, "Predicting Residual Stresses in Gas Turbine Components," JOM, 1995, no. 10: 69-71

[10] R. I. Ramakrishman and T. E. Howson, "Modeling the heat Treatment of Superalloys," JOM,44 (6) (1992), 29-32

[11] D.Persampieri, "Process Modeling for Improved heat Treating," Advanced Materials \& Processes, 1991, no:3: 19-23

[12] D. L. Klastrom, "Heat Treatment Cracking of Superalloys," Advanced Materials \& Processes, 1996, no.4: 40EE-40HH

[13] K.M.Chang and B.Wu, "A New Approach to Evaluate the Quench Cracking Resistance of P/M Superalloy," 1st International Non-Ferrous Processing and Technology, ed T.Bains and D.S.Mackenzie, ASM International (1997) 477-481

[14] Valerie L. Keefer, "Fracture Mechanics Approach in Studying the Quench Cracking Behavior of the High Strength Superalloy Udimet 720," (MS thesis, West Virginia University, 1998)

[15] J.Mao, V.L.Keefer, K.M.Chang and D.Furrer, "An Investigation on Quench Cracking Behavior of Superalloy Udimet 720 Using Fracture Mechanics Approach," Journal of Materials and Engineering Performance, (accepted, 1999)

[16] H. Tada, P. Paris, and G. Irvin, The Stress Analysis of Cracks Handbook, (Del Research Corp. 1973), 2.10-2.12

[17] Keh-Minn Chang, "Critical Issues of PM Turbine Disks," Acta Metallurgica Sinica, 9 (6) (1996), 467-471

[18] R.D.Kissinger, "Cooling Path Dependent Behavior of a Supersolvus Heat Treated Nickel Base Superalloy," Superalloy 1996 ed. R.D.Kissinger et al. The Minerals, Metals and Materials Society (1996) 689-695

[19] S.T.Wlodek, M.Keely and D.A.Alden, "The Structure of Rene88DT," Superalloy 1996, ed. R.D.Kissinger et al. The Minerals, Metals and Materials Society (1996) 129-136

[20] H.Hattori, M.Takekawa, D.Furrer and R.J.Noel, "Evaluation of P/M U720 for Gas Turbine Engine Disk Application," Superalloy 1996, ed. R.D.Kissinger et al. The Minerals, Metals and Materials Society (1996) 705-711 